\title{
Retraction Note to: Antioxidants and ROS scavenging ability in ten Darjeeling tea clones may serve as markers for selection of potentially adapted clones against abiotic stress
}

\author{
Nirjhar Dasgupta ${ }^{1}$ Prosenjit Biswas ${ }^{2} \cdot$ Rakesh Kumar $^{2} \cdot$ Narendra Kumar $^{2}$. \\ Biswajit Bera $^{3} \cdot$ Sauren Das ${ }^{1}$
}

Published online: 3 May 2016

(C) Prof. H.S. Srivastava Foundation for Science and Society 2016

Retraction Note to: Physiol Mol Biol Plants 19(3):421-433

DOI 10.1007/s12298-013-0187-1

This article has been retracted by the editor on account of falsification/fabrication of data in Figure 3 of the above paper, as the corresponding author failed to defend the charge levelled initially at Pubpeer and validated subsequently through an editorial enquiry at PMBP, and also failed to reproduce fresh results sought by the editor. The employer of the author has been intimated.

The online version of the original article can be found at http://dx.doi.org/ 10.1007/s12298-013-0187-1.

Sauren Das

sauren@isical.ac.in

Agricultural and Ecological Research Unit, Indian Statistical Institute, 203, B.T. Road, Kolkata 700108, India

2 Darjeeling Tea Research and Development Centre, A.K. Mukherjee Road, Kurseong, Darjeeling 734203, India

3 Tea Board of India, Ministry of Commerce and Industry, Government of India, 14, B.T.M Sarani, Kolkata 700001, India 